This item was submitted to Loughborough's Research Repository by the author.

Items in Figshare are protected by copyright, with all rights reserved, unless otherwise indicated.

\title{
Transparency in product design: investigating design intentions and consumers' interpretations
}

PLEASE CITE THE PUBLISHED VERSION

https://doi.org/10.1080/09544828.2018.1515426

\section{PUBLISHER}

(c) Taylor \& Francis

\section{VERSION}

AM (Accepted Manuscript)

\section{PUBLISHER STATEMENT}

This is an Accepted Manuscript of an article published by Taylor \& Francis in Journal of Engineering Design on 29 August 2018, available online: http://www.tandfonline.com/10.1080/09544828.2018.1515426.

\section{LICENCE}

CC BY-NC-ND 4.0

\section{REPOSITORY RECORD}

Cheng, Peiyao, Ruth Mugge, and Cees de Bont. 2019. "Transparency in Product Design: Investigating Design Intentions and Consumers' Interpretations”. figshare. https://hdl.handle.net/2134/35171. 


\title{
Transparency in Product Design: Investigating Design Intentions and Consumers' Interpretations
}

\author{
Peiyao Cheng ${ }^{\mathrm{a} *}$, Ruth Mugge ${ }^{\mathrm{b}}$ and Cees de Bont ${ }^{\mathrm{c}}$ \\ a*Design Department, Harbin Institute of Technology Shenzhen, Shenzhen, China; \\ chengpeiyao@gmail.com
}

Peiyao Cheng is Assistant Professor at the Design Department, Harbin Institute of Technology Shenzhen. Her research focuses on investigating the influences of product appearance on consumer response. She has presented her works in several international conferences and published her work in Design Studies.

${ }^{b}$ Department of Product Innovation Management, Faculty of Industrial Design

Engineering, Delft University of Technology, Delft, the Netherlands;

r.mugge@tudelft.nl

Ruth Mugge is Professor of Design for Sustainable Consumer Behavior at the department Product Innovation Management, Delft University of Technology. Her current research focuses on sustainable consumer behaviour. She has published her words in such journals as Design Studies, Journal of Engineering Design, Applied Ergonomics, British Journal of Psychology, Journal of Product Innovation Management, International Journal of Design, and the Design Journal.

${ }^{c}$ Loughborough Design School, Loughborough University, Loughborough, UK.

\section{C.J.De-Bont@lboro.ac.uk}

Cees de Bont is currently Dean of Loughborough Design School. His research covers design education, consumer behaviour, innovation adoption, design methods and networked innovation. He has published extensively in international journals, including Design Studies, Design Issues, the Journal of Product Innovation Management, the International Journal of Cultural and Creative Industries and the Journal of Design, Business and Society. 


\title{
Transparency in Product Design: Investigating Design Intentions and Consumers' Interpretations
}

\author{
Transparency is used in product design across various product categories. Because of \\ the physical property of letting light go through, transparency can create unique \\ visual styles. Transparency can also communicate additional information as a result \\ of what is situated underneath the product cover, which prompts different consumers' \\ interpretations. To support designers to use transparency effectively, this research \\ aims to explore the use of transparency in product design to provide an overview of \\ the design intentions of using transparency. Specifically, two studies were conducted. \\ In Study 1, in-depth interviews with experienced designers $(\mathrm{N}=6)$ were conducted \\ and the results revealed the overview of the following five design intentions of using \\ transparency in product design: enrich visual appeal, enrich product experience, \\ improve product usability, facilitate consumers' comprehension and demonstrate \\ product functionality. The overview was further validated through consumer \\ interviews $(\mathrm{N}=13)$ in Study 2.
}

Keywords: consumers' interpretation; design intention; product design; transparency.

\section{Introduction}

Product design can significantly influence consumers' perception of a product, consumers' experience and their preference (Bloch 1995, Creusen and Schoormans 2005, Crilly, Moultrie, and Clarkson 2004). As designers are responsible for shaping products to trigger certain responses (Crilly et al. 2008), a number of studies have investigated the effects of different product features. Specifically, prior research has found that novelty affects consumers' aesthetic preference (Hekkert, Snelders, and Wieringen 2003), their perception of the product's performance quality (Mugge and Schoormans 2012a, Mugge, Dahl, and Schoormans 2017), and consumers' perception of the product's usability (Mugge and Schoormans 2012b). Typicality (Blijlevens et al. 2012, Hekkert, Snelders, and Wieringen 
2003) and unity (Post, Blijlevens, and Hekkert 2016, Veryzer and Hutchinson 1998) affect consumers' aesthetic preference. Visual complexity has been demonstrated to be related to consumers' perception of product functionality (Creusen, Veryzer, and Schoormans 2010) and environmental friendliness (Lee, Jung, and Chu 2015). Harmony affects consumers' aesthetic preference (Kumar and Garg 2010) and their perception of the product's performance quality (Mugge, Dahl, and Schoormans 2017). Previous studies have also investigated the different product personality traits that product designs can convey (Desmet, Nicolas, and Schoormans 2008, Mugge, Govers, and Schoormans 2009) and the effects of certain product personality traits on consumers' perception of product performance quality (Mugge 2011). Furthermore, different toolkits have been developed to support designers in styling activities (Giannini, Monti, and Podehl 2006, Chen and Owen 1998, Hsiao and Wang 1998, Camargo and Henson 2015, Barnes and Lillford 2009) and in material selection activities (Kesteren, Bruijn, and Stappers 2008, Karana et al. 2015).

In summary, these studies have provided valuable support to designers by uncovering the effects of different product features on consumer responses. However, transparency, another product feature that designers consider while designing (Ashby and Johnson 2002, Karana, Hekkert, and Kandachar 2009), has not been investigated thus far. Transparency by definition means 'having the property of transmitting light'. Depending on how much light can go through the surface, transparency can be further measured by four levels ranging from completely blocking light to allowing all light to pass through. These four levels are opaque, translucent, transparent, and water-clear or optical quality (Ashby and Johnson 2002). Opaque materials completely block light, while materials in the rest of the three levels allow light to pass through. As a result, consumers can see the situation underneath transparent materials, while they cannot see underneath opaque materials. 
Translucent materials allow consumers to see the underlying situation in a blurry manner. The optical quality is mainly used for determining the performance characteristics of optical instruments (e.g., glasses and microscopes).

When transparency is used in product design, it can create diverse effects. First, transparency can create unique visual styles. For instance, launched in 1998, Apple iMac G3 was embodied with the glossy translucent cover, which created a distinct look at that time (Person and Snelders 2010). Next, through the transparent cover of iMac G3, designers can reveal the technical details hidden underneath, which prompted different consumers' interpretations. At that time, people felt that Silicon Valley technologies were mysterious. The transparent cover of the Apple iMac G3 thus enabled people to see technical details under the product cover (Coates 2003). As a result, consumers faced a completely new experience: they perceived the Apple iMac G3 not as a cold office device but as a friendly and modern household product (Dell'Era et al. 2011). Moreover, seeing the internal situation through transparency can influence consumers' perception and their behaviour (Lockton, Harrison, and Stanton 2010). For example, the Dyson vacuum cleaner is featured with a transparent dust container, which allows consumers to observe how dust is sucked and the amount of dust that is accumulated. As a result, consumers perceive the effectiveness of the vacuum cleaner. Consumers can also learn when to clean the dust container.

Transparency has drawn research attention in the packaging design area. Prior research found that consumers prefer transparent packaging because it provides them with a chance to see the food inside (Fernqvist, Olsson, and Spendrup 2015, Simmonds and Spence 2017). In comparison to opaque packaging, transparent packaging can enhance consumers' perception of trustworthiness (Billeter, Zhu, and Inman 2012), consumers' 
evaluation of food quality and freshness (Simmonds, Woods, and Spence 2018), consumers' willingness to buy (Simmonds, Woods, and Spence 2018, Billeter, Zhu, and Inman 2012), and the amount of food consumed (Deng and Srinivasan 2013). It was also found that the positive effects of transparent packaging are triggered when the inside food is visually attractive (Deng and Srinivasan 2013, Billeter, Zhu, and Inman 2012).

Correspondingly, when transparency is used in product design, consumers can see the internal components and consumers can interpret the products differently. Thus far, several studies focusing on materials and design intentions provide fragmented insights into transparency. For example, Karana, Hekkert, and Kandachar (2008) have found that transparency is one of factors that designers consider when selecting materials. Karana, Hekkert, and Kandachar (2009) have also found that designers tend to use transparent/translucent materials to convey the meaning 'sexy'. Lockton, Harrison, and Stanton (2010) have suggested that transparency can influence consumers' perception and behaviour. Yet, as these studies did not focus on transparency particularly, they can only provide limited support for the effective use of transparency in product design. Thus, more research is needed with a specific focus on transparency.

The present research contributes to the design literature by investigating the product feature of transparency. In particular, the investigation of transparency can provide insights on how additional information underneath the product cover influences consumers' interpretations. In prior research, product features (e.g., novelty, visual complexity and harmony) influence consumers' perceptions through inference making. For example, consumers tend to relate a novel-looking product with superior performance quality because they associate the novel look with advanced integrated technology, although product design and functionality are objectively independent from each other (Mugge and 
Schoormans 2012a). In contrast, transparency makes the influences by conveying additional information. For example, when consumers encounter a Dyson vacuum cleaner, their perception of effectiveness is attributed to the inferences evoked not only by the product's complex design but also by its transparent design, which enables the consumers to see the suction process.

This research aims to generate an overview of diverse effects created by transparency in product design. This overview can inform designers what additional information can be conveyed through transparency and how consumers interpret the additional information. Furthermore, this overview can inform designers how the diverse effects of transparency relate to each other. Specifically, designers may intend to use transparency for triggering one effect but unintentionally trigger other effects as well. For instance, while designing a smartphone, designers may intend to use transparency to create a unique visual style to stand out from competitors. Yet, transparency also reveals the electronic sensors and chips inside a smartphone, which can trigger consumers' confusion. By providing an overview of the diverse effects of transparency, we can help designers prevent such undesirable effect(s) of using transparency and thus make more effective use of this product feature in new product designs.

\section{Transparency in Product Design: Design Intentions and consumers' interpretations}

To obtain an overview of the diverse effects triggered by transparency in product design, it is insightful to explore what designers intend to convey through transparency. While designing, designers have multiple intentions, such as facilitating consumers' comprehension of product functionalities, assisting consumers' categorisation of product 
categories and triggering consumers' emotional responses (Crilly, Moultrie, and Clarkson 2009). To fulfil their intention(s), designers use different product features (e.g., novelty, visual complexity and transparency). Following this, the use of transparency in product design can be considered a medium for realising certain design intentions and exploring the underlying design intentions can thus help us to obtain an overview of the diverse effects created by transparency.

However, to obtain a comprehensive overview, it is important to comprehend that these intentions may not necessarily be fulfilled. Although design intentions aim at triggering certain effects, consumers may not interpret product design in the ways intended by designers (Crilly et al. 2008). For example, although designers may intend to use transparency in the Dyson vacuum cleaner to demonstrate its effectiveness by showing how it sucks in dust, consumers' perception of effectiveness depends on whether they notice the suction process and successfully process it. In fact, prior research has empirically examined the correspondences between design intentions and consumers' interpretations in different contexts with the results showing the differences (Ahmed and Boelskifte 2006, Smets and Overbeeke 1995).

Because of the possible differences between design intentions and consumers' interpretations, it is necessary to explore how consumers interpret transparency, which can validate design intentions to use transparency, resulting in a comprehensive overview for the effective use of transparency in product design. Two studies were conducted. In Study 1, we explored design intentions for using transparency in product design by interviewing experienced designers. Specifically, designers were asked to categorize 32 products that used transparency according to the intentions of using transparency. They were also asked to clarify the rationales for making the categorization. These insights were recorded and 
analysed, which resulted in an overview of intentions for using transparency in product design. Next, in Study 2, consumers' interviews were conducted to learn consumers' interpretations of transparency in product design. To validate the findings from Study 1, the data of Study 2 was analysed by using the results of Study 1 as the coding framework. The two studies are reported in the following two sections. Subsequently, the general discussion follows, in which theoretical contributions and practical implications are discussed, as well as the limitations and future research possibilities.

\section{Study 1: Investigation of Design Intentions for Using Transparency in Product Design}

Design intentions can be learned by directly asking designers and through marketing materials, including product descriptions, advertisements and product manuals (Da Silva, Crilly, and Hekkert 2015). To learn the design intentions of using transparency in product design, we collected information through two methods. First, we collected a large set of diverse product examples in which transparency was used. The purpose of collecting a large set of product examples was to cover the diverse effects of transparency and thereby gain a comprehensive overview. Because of the large number of collected product examples, it was difficult to interview the actual designers about their design intentions. Hence, we decided to interview experienced designers about the design intentions that they anticipated on the basis of the product designs. Although the identified design intentions were anticipated, we believe that they corresponded strongly to the actual design intentions as experienced designers are trained to identify the underlying design intentions for other products. Furthermore, to validate the anticipated design intentions found from the design interviews, an additional analysis was conducted by collecting and analysing product 
descriptions from marketing materials that were related to the actual design intentions. Throughout this article, the expression 'design intention(s)' refers to the anticipated design intention(s).

\subsection{Study 1: Investigation of design intentions through designer interviews}

\subsubsection{Method}

Participants

In-depth interviews were conducted with six experienced industrial designers. The participants were collected through personal contacts. Seven potential candidates were contacted and one potential participant did not join the study because of schedule incompatibility. These participants were contacted because of their several years of practical experience and the excellent quality of their design works. They had designed products for many years, mainly focusing on designing consumer durables (see Table 1 for details), such as consumer electronics, automotive and furniture. Moreover, they had won international design prize(s) (e.g., RedDot and iF) for their design work(s). Therefore, because of their expertise, they were equipped with the knowledge required to explain how and why transparency was used to fulfil certain intentions.

\section{Stimuli}

Consumer durables were collected as stimuli materials. Because this research involved consumer interviews in Study 2, we selected consumer products as the stimuli to ensure that consumers were familiar with them so that they could express their opinions on these 
products. Furthermore, consumers often invest more time and efforts to interpret productrelated information while encountering consumer durables than fast-moving consumer goods (Creusen and Schoormans 2005), which makes it possible to explore consumers' interpretations of consumer durables. Moreover, consumer durables are often evaluated and purchased with different motives, including aesthetics, ease of use and powerful performance (Blijlevens, Creusen, and Schoormans 2009, Mugge, Dahl, and Schoormans 2017), so designers need to communicate multiple messages while designing consumer durables.

[Table 1 near here]

Stimuli materials were collected from different product categories of consumer durables. Specifically, we first collected pictures of products and concepts that were partly or fully made of transparent or translucent materials. As a result, more than 100 products and concepts were collected through an extensive Internet search using the keywords 'transparency', 'transparent', 'transparent products', 'translucent' and 'translucent products'. To ensure coverage of the full range of possible intentions to use transparency, we selected products and concepts from different product categories, such as household products, kitchen appliances, lifestyle products and consumer electronics. To obtain a practical number of stimuli materials for the designer interviews, we excluded some products and concepts that were very similar in appearance and where transparency was used for similar products and parts. For each product category, we selected the most wellknown products or brands. Consequently, 32 products were included as the final stimuli. These products covered different categories and differed in their levels of innovativeness. Specifically, some products were highly innovative because these products allowed 
consumers to do things they could never do previously, while other products provide incrementally innovative functions, based on improvements of current technology and functionality (Garcia and Calantone 2002). The stimuli were presented on A5 size cards in portrait orientation, with the product picture(s) in colour and the name of the product category. The pictures of the products were standardised in size $(11 \mathrm{~cm} \times 12.5 \mathrm{~cm})$ and in resolution (300 dots per inch [dpi]). The brand logo was digitally removed. If a product example was very innovative and potentially unfamiliar to the participants, its key features were listed. Appendix A presents the stimuli used in this study.

\section{Procedure}

The participants were invited to the laboratory individually. When they arrived, they were first informed about the aim and the procedure of the interview and were asked permission to record and photograph their responses. Next, the interviews started with the following warm-up question: 'When designing, when would you consider using transparent materials in product design?' This question aimed to familiarize the participant to the topic of the interview: transparency in product design. With further probing questions, the participants were encouraged to talk about the various purposes of and intentions to use transparency. Subsequently, the participants were asked to perform a categorisation task. They were asked to classify the 32 stimuli into different groups on the basis of the design intentions to use transparency. The stimuli were presented in a random order. The participants were asked to think aloud while categorising. In particular, they were told the following: 'All of these examples involve transparent/translucent materials. Based on your understanding, what do you think designers intend to express by using transparent/opaque materials in 
these examples? Could you categorise them based on different intentions?' They were free to choose the number of groups and the number of stimuli in each group (Handel and Imai 1972). The goal of this categorisation task was to sort the stimuli into different groups according to mutual similarities and differences considering the intention to use transparency in the stimuli products. As the usage of transparency in product design can result from a combination of multiple design intentions (Crilly, Moultrie, and Clarkson 2009), a categorisation task can help participants distinguish the underlying design intentions and determine the prominence of each design intention. While completing the categorisation, the participants were asked to label each category with an explicit name that illustrated the design intention. They were also required to explain the name and to clarify why certain stimuli belonged to the same group. For each group, they were asked to explain the following: 'Why are the transparent materials used here? What intentions do the designers want to express?' The final categorisations were photographed. After the categorisation task, the participants were asked to cite other interesting examples that used transparency in product design driven by design intentions that were not mentioned here. No other product examples were mentioned, and all of the participants indicated that the selected examples were sufficient to cover the various design intentions to use transparency in product design. The interviews lasted between 45 and 115 minutes.

\section{Data processing}

All of the interviews were fully transcribed. Content analysis was performed using Atlas.it software. Because of the explorative purpose of this study, the data were processed inductively. The interviews were coded for patterns and themes in the data directly 
(Thomas 2006). This coding process was conducted interview by interview and resulted in a number of codes. The codes that were not directly related to our research goals were removed from further analyses. Then, the remaining codes were further compared and codes with similar meanings were merged. For instance, the codes 'fresh' and 'clean' were merged into the code 'aesthetic meanings' because they described the meaning that a product design communicates to consumers through its look. Moreover, the codes that shared the same meaning were grouped into a single theme. Finally, this process resulted in 11 codes distributed over five themes that were directly related to the design intentions to use transparency in product design. The point of saturation was reached after the third interview, and coding the remaining interviews did not reveal any significant new themes, which suggested the sufficiency of the sample size. The coding was checked by two researchers who were unaware of the research goals of the study. The following section explains each theme, together with the codes for the theme and the corresponding quotations as well as product examples.

\subsubsection{Results}

In general, the interviews ran smoothly. Regarding the categorisation task, the participants had a few difficulties. For some examples, the participants felt uncertain about the underlying design intentions to use transparency. They considered them the designers' personal choices. After some revisions and adjustments, the participants were satisfied with the final categorisation. In terms of the participants' opinions on transparency, they mentioned that transparency was an aspect they used while designing products. They also mentioned that the most prominent characteristic of transparency was the opportunity to see through a product into its internal components. The participants particularly highlighted 
that because the use of transparency increased manufacturing costs, there were often strong motivations to choose transparency.

The results of the categorisation task did not highly correspond. As the participants were asked to categorise the stimuli freely, they created various categorisations based on different rationales and used different words to label each category. For example, one participant categorised the stimuli on the basis of the degree of necessity of transparency. He labelled his three categories 'transparency was necessary', 'transparency was partly necessary' and 'transparency was not necessary'. In contrast, another participant made his categorisation on the basis of aesthetic intention or functional intention. The stimuli products were classified into four main groups: 'improve aesthetic value', 'create artist statements', 'show physical operation process' and 'allow consumers to appreciate the process'. Because of the different rationales used by the participants, the results of the categorisation task were not directly used for the analyses. Instead, the categorisation task was used as a tool to push the participants to think reflectively and clarify their opinions. However, the insights provided during the categorisation task corresponded strongly. Consequently, the data analyses were based on the participants' thoughts expressed during the categorisation task.

Five themes emerged from the content analysis: enrich visual appeal, enrich product experience, improve product usability, facilitate consumers' comprehension and demonstrate product functionality. The five themes were directly related to the different intentions of the use of transparency in product design, and they provided an overview of the use of transparency in product design.

\section{Enrich visual appeal}


Transparency can be used to enrich the appeal of a product design. By visual appeal, we mean the various visual aspects related to a product design, relating to the aesthetic and symbolic role of a product design (Creusen and Schoormans 2005). Furthermore, four different ways of using transparency to 'enrich visual appeal' were identified: create special visual effects, trigger certain aesthetic meanings, improve visual complexity and introduce a novel style.

First, transparency can create different special visual effects for product design. The physical property of letting light pass through surfaces is naturally shared by water, ice, diamonds and crystals, which create special visual effects. Thus, when transparency is used in product design, it copies these special effects of nature, which the participants considered to be special visual effects, such as the effects of ice cubes and ocean-like creatures.

Second, transparency can be used to express certain aesthetic meanings. By aesthetic meanings, we refer to the abstract and expressive meanings that a product communicates to its consumers through its appearance (Blijlevens, Creusen, and Schoormans 2009). For example, by looking at a product, consumers can consider it to be cheerful, modern or playful (Creusen and Schoormans 2005, Blijlevens, Creusen, and Schoormans 2009). The aesthetic meanings are related to the symbolic value of a product design referred to by Creusen and Schoormans (2005) because the aesthetic meanings expressed by the product can also communicate the image of the owners. For instance, owning a professional looking laptop can help the owner create a professional self-image.

Third, transparency can improve the visual complexity of product design. As demonstrated in prior research, moderately improving the visual complexity of product design can make a product aesthetically appealing (Berlyne 1971). The use of transparency in product design can improve their visual complexity by creating contrasts between 
different parts and allowing the internal parts to be visible.

Fourth, transparency can create a novel style when it is rarely used in a product category. Designing products that deviate from a typical example in a product category can make a product look new. Thus, when transparency is rarely used in a product category, the use of transparency can create a novel-looking product. The codes and the corresponding quotes can be found in Table 2.

[Figure 1 near here]

[Table 2 near here]

\section{Enrich product experience}

Another design intention to use transparency was 'enrich product experience'. By using the term 'product experience', we refer to the consumers' subjective experience on the aesthetic level, which concerns 'a product's capacity to delight one or more of our sensory modalities' (Desmet and Hekkert 2007). Specifically, transparency can 'enrich product experience' in three ways: it can enrich consumers' sensorial experience by appreciating the process, by appreciating the inside contents, and by decreasing the psychological distance between products and consumers. The quotes for this design intention can be found in Table 3.

Consumers' sensorial experience is an important source for the overall product experience (Desmet and Hekkert 2007). How a product looks contributes to consumers' sensorial experience of the product. When transparency is involved in a product design, the internal parts of a product are exposed, which allows consumers to observe the process. For some product designs, particularly those of kitchen appliances, observing how food is 
cooking can be pleasant, such as seeing how bread browns (No. 21) and how coffee drips drop by drop (No. 25). Compared with opaque exteriors, transparency creates the opportunity for consumers to observe and appreciate the process, which contributes to their sensorial experience.

Furthermore, the use of transparency can create one more channel of sensorial experience by offering an appreciation of the inside. For example, a transparent cover exposes the fire inside a stove. When consumers see it, they feel warm. In other words, in addition to feeling warm in terms of physical temperature, seeing the fire makes consumers feel warm psychologically.

In addition, transparency can decrease the psychological distance between a product and its consumers, leading to an engaging experience. When seeing a product's internal components, consumers feel that the product is psychologically closer to them. One participant offered the following explanation: 'If you want to erase the barrier, you want people to see, don't want to separate [the product and consumers] ... then you use transparent materials. Users can become more involved. Transparency is more inviting (P6)'. One participant further explained this with the example of iMac G3: 'Transparent material gives the product higher level experience change. It is not any more a solid piece product (P3)'. Moreover, such an engaging experience is related to the previous two codes, enriching consumers' sensorial experience by appreciating the process and the inside contents, because both can decrease the psychological distances between products and consumers. However, we decide to separate this code because the engaging experience can be created without seeing any enjoyable process or meaningful inside contents. The engaging experience can be created simply by seeing through a product cover, such as the example of a radio (see Figure 2c, No. 27), which is empty inside. 
[Figure 2 near here]

[Table 3 near here]

Improve product usability

'Improve product usability' was identified as another design intention to use transparency in product design. Product usability is determined by the effectiveness and efficiency of a product to achieve a goal and by consumers' satisfaction with using the product to achieve a goal (Jordan 1998). When transparency is used in product design, it can communicate information related to the product's operation, which can contribute to the efficiency of using a product and to consumers' satisfaction. In particular, transparency can communicate three types of information: 1) the product's operation status, 2) the immediate feedback and 3) the outcome of the product's operation. By communicating these three types of information, the participants expected the products to be more usable and interactive.

Regarding the communication of the product's operation status, the underlying design intention was to inform consumers about whether the product was working and whether the product was working normally. In the example of a washing machine (No. 18), a transparent door allowed consumers to see whether the washing machine worked normally.

Another design intention was to communicate immediate feedback regarding the product's operation, including how much of the task was completed. The communication of the present situation of product operation can provide suggestions on how to further operate the product, which largely improves product usability. For instance, for kitchen appliances, it is important to inform consumers of the present situation of food, which allows them to 
better control the cooking process.

Furthermore, once a product has completed its work, transparency could be used to communicate the outcome of the product operation, such as the amount of dust collected by the vacuum cleaner (No. 11) and the amount of coffee made by the coffee maker (No. 29) (see Table 4 for the codes and corresponding quotes).

[Table 4 near here]

[Figure 3 near here]

\section{Facilitate consumers' comprehension}

The theme 'facilitate consumers' comprehension' emerged from the data analysis. The participants believed that the involvement of transparency in product design could show the working process of the products. As a result, consumers may gain a better understanding of the products because they see the immediate results of the innovative technology, which helps them grasp its benefits and features. One participant explained the following: 'When we are using transparent materials, the product itself will give us some idea of the function of the product we are talking about (P3)'. In the example of the Dyson vacuum cleaner, whose innovative technology of a dual-cyclone suction system challenges consumers' comprehension, consumers can directly see how dust is sucked into the container and how both the airflow and dust twist inside it, which helps them to understand the benefits of this innovative technology. Table 5 presents the code and corresponding quote.

[Table 5 near here]

[Figure 4 near here] 
To facilitate consumers' comprehension, the participants further explained that the exposed parts should communicate the dynamic working process of the innovative technology integrated in the innovative products, rather than showing their static content. One participant explained the following: 'People can see what happens inside... Not just to see the content inside. People can see what is happening when it works'. In addition, the enhancement of consumers' comprehension of innovative products may differ across product categories. The participants considered that showing the working process could be helpful for consumer durables driven by mechanical components, such as the Dyson vacuum cleaner and Tefal ActiFryer that integrates the rapid air technology to fry food with little oil. However, for consumer electronics (e.g., digital camera and classic PC), showing the working process may not be helpful for enhancing consumers' comprehension, as they may not understand how the integrated chips and sensors work.

Furthermore, the design intention 'facilitate consumers' comprehension' was more prominent for products with integrated innovative technology, which are in the early stage of the product lifecycle. As innovative technologies could challenge consumers' comprehension, the participants highlighted the necessity of exposing the working process to assist consumers' comprehension. In contrast, for products that did not involve innovative technologies, although the working process could be exposed through transparency, the participants considered that the choice of transparency was driven by different intentions, such as 'enrich product experience' and 'improve product usability'. For example, one participant mentioned the following:

'This (Dyson vacuum cleaner, No. 12) is also showing its working process. But this is different from another example of vacuum cleaner (No. 11. See Figure 3c) because this (No. 12) is a new technology. It demonstrates the technological process. This is more about how the internal 
filter works'.

\section{Demonstrate product functionality}

Products differ in the degree to which they perform their basic functions (Creusen \&

Schoormans, 2005). For example, a vacuum cleaner with high suction power can perform its task more effectively than the one with low suction power. By 'demonstrate product functionality', we refer to the effectiveness of a product fulfilling its utilitarian task. Designers can design product appearance to demonstrate the effectiveness of product performance. The participants believed that transparency could be used to 'demonstrate product functionality' by showing the effectiveness of the adopted technology. As transparent parts generally expose internal components to consumers, companies need to devote additional efforts and costs to the design of the internal components to make them look organised and attractive to consumers. As a result, the participants considered that exposing internal components by using transparency became a way for companies to demonstrate their technological abilities. One participant mentioned the following:

'This is their strategy [to show the internal structure]... All of the vacuum cleaner manufacturers would like people to see it, because it is expensive. If you want people to look inside, it means that the internal components need to look beautiful'.

[Table 6 near here]

[Figure 5 near here] 
Specifically, two types of product functionality demonstrations were identified (see Table 6). When the adopted technology was very innovative, transparency was used to highlight the innovative technology and thereby communicate the product's powerful functionality. When the technology was a common one, the use of transparency improved the novelty of the product design and indicated that some improvements had been made to this product, which prompted consumers' perception of innovative product functionality (Mugge and Schoormans 2012a). However, when transparency is widely used in a product category, consumers may relate the use of transparency to neither novelty nor innovative product functionality.

\subsection{Additional analysis on design intentions through marketing materials}

In Study 1, the design intentions were collected through interviews with experienced designers. Although these designers had the expertise to explain the underlying design intentions, these design intentions remained anticipated rather than actual. Being aware of the possible differences between the anticipated and actual design intentions, we aimed to validate the findings of the interviews with experienced designers by conducting an additional analysis to explore the actual design intentions.

From the official websites of these products, we collected the information related to the design intentions of using transparency in these products. For 16 (of 32) products, information related to the actual design intentions for using transparency was collected. Based on the collected descriptions, content analysis was conducted to identify and analyse the actual design intentions to use transparency. As a result, several actual design intentions were identified. These actual design intentions were compared with the themes and codes from the designer interviews. Appendix B provides a table summarising the identified 
design intentions and their correspondence to the design intentions found in the designer interviews. To conclude, the results suggested that the uncovered actual design intentions corresponded to the anticipated design intentions as identified in the designer interviews.

\subsection{Analysis of design intentions distributed in different product categories}

This study presents an overview of five design intentions of using transparency in product design. The prominence of design intentions can be different for different product categories. To understand the prominence, we analysed the distribution of design intentions in different product categories. Specifically, on the basis of the participants' opinions provided in the interviews, we assigned each stimuli product to the mentioned design intentions. Sometimes, when several design intentions were mentioned, we assigned the stimuli product to the corresponding multiple design intentions. Next, we grouped the stimuli products into four product categories on the basis of their primary utilitarian function: consumer electronics (9 products), household products (10 products), kitchen appliances (6 products) and lifestyle products ( 7 products). In particular, consumer electronics included the digital equipment used at home, such as tablet, television and digital camera. For household products, we referred to the products that are used at home for a utilitarian purpose excluding cooking, such as air conditioner, washing machine and vacuum cleaner. Kitchen appliances refer to the products that are mainly used for cooking, such as fryer, toaster and kettle. Lifestyle products refer to the products that are used mainly for hedonic purposes, such as oil diffuser, lighting and coffee dripper. Finally, for each product category, we counted the times that each design intention was mentioned and calculated the percentage of each design intention among the total number of design intentions mentioned in the product category. Figure 6 shows how design intentions 
differed among the product categories.

For consumer electronics, the prominent design intentions for using transparency include enrich visual appeal and demonstrate product functionality. As consumer electronics often compete in terms of functional performance, designers intend to use transparency as a way to demonstrate product functionality by showing internal components.

[Figure 6 near here]

For household products, improve product usability is the most important consideration for using transparency in product design. Household products often assist consumers to fulfil utilitarian goals at home (e.g., washing machine for washing clothes and vacuum cleaner for cleaning floors). Thus, product usability matters because it determines whether the products can fulfil the goals in an efficient and convenient manner. In addition, as household products differ in terms of their capability to fulfil utilitarian goals (e.g., the different suction power of vacuum cleaner), demonstrate product functionality is considered. The visual appeal of household products also matters because consumers often own these products for years and they pay attention to products' looks.

Similarly, improve product usability is a prominent intention for using transparency in kitchen appliances because seeing the present situation of food can provide consumers with better control of the cooking, which determines whether the cooked food is delicious. Moreover, as seeing the cooking process is an enjoyable experience, enrich product experience is also covered in the intentions of using transparency in kitchen appliances. For lifestyle products, enrich visual appeal and enrich product experience become 
important because these products fulfil hedonic purposes. Consequently, using transparency to enrich product experience becomes prominent. Moreover, as visual appeal is an important factor of product experience, enrich visual appeal is considered.

In this analysis, the design intention facilitate consumers' comprehension is not prominent in any product category because its prominence is influenced by the stage of the product lifecycle. Specifically, this design intention is more prominent for products in the early stage of product lifecycle because the product innovativeness often hinders consumers' comprehension. Moreover, this intention is more relevant for household products and kitchen appliances, which are driven mechanically. Showing how innovative technology works is likely to assist consumers' comprehension.

To conclude, Study 1 reveals an overview of design intentions of using transparency in product design. This additional analysis further shows the influences of the product category and the stage of the product lifecycle on the prominent design intentions.

\subsection{Discussion of Study 1}

In Study 1, by interviewing experienced designers, five different design intentions of using transparency in product design were identified: enrich visual appeal, enrich product experience, improve product usability, facilitate consumers' comprehension and demonstrate product functionality. Within each design intention, the specific codes also explain the ways to achieve it.

The identified five design intentions represent the range of concerns that designers intended for using transparency in product design. They are distinct from each other, but they are not necessarily mutually exclusive. These design intentions can relate to each other. In fact, while designing, designers may have different design intentions that are 
interrelated (Crilly, Moultrie, and Clarkson 2009). In the example of the Dyson vacuum cleaner, the design intention facilitate consumers' comprehension is fulfilled by using transparency to show the dynamic working process. While exposing this working process, transparency also reveals the present situation of the cleaning process, which relates to the design intention improve product usability. Moreover, by seeing the suction process, consumers can learn about the product's effectiveness, which relates to the design intention demonstrate product functionality.

\section{Study 2: Investigation of consumers' interpretations of transparency in product design}

Study 1 results in an overview of the design intentions of using transparency in product design. Study 2 aims to validate this overview through investigating how consumers interpreted transparency in product design. When encountering the same product designs, designers and consumers form different perceptions and use different adjectives to describe their perceptions (Hsu, Chuang, and Chang 2000, Blijlevens, Creusen, and Schoormans 2009). To prevent the possible differences, we believe that we can learn consumers' interpretations more accurately by asking consumers to express their opinions in their own vocabulary. Therefore, we conducted consumer interviews with open questions.

\subsection{Method}

\subsubsection{Participants}

In-depth interviews were conducted with consumers in a big city in China. Thirteen consumers were recruited (six male participants, ranging in age from 25 to 52 years with a mean age of 34 years). None of the participants had a product-design-related background. 
These participants were collected through personal contacts. First, they were informed that the interview had an academic purpose and the topic was about their opinions on consumer durables. Next, they were asked whether they were interested in participating and making an appointment. All of the contacted participants joined the interviews. They received a gift for their participation.

\subsubsection{Stimuli}

To make the interview feasible for the participants, 16 product examples were selected as the stimuli materials (see Appendix A). These stimuli were selected from the 32 stimuli products used in Study 1. Based on the participants' opinions in Study 1, some product examples were excluded because the usage of transparency was considered a personal choice of designers, rather than driven by clear and strong design intentions. The selected product examples covered different design intentions and product categories.

\subsubsection{Procedure}

The participants were invited to an enclosed and quiet environment. They were first informed about the aim and procedure of the interview. Next, they were asked permission to record and photograph their responses. The interview was conducted in two parts. In the first part, the participants were presented with 16 product examples one by one and were asked to talk about their general opinions and feelings towards these products. These product examples were presented in a random order. In the second part, the participants were asked about their opinions and feelings towards these products one more time, with a specific focus on the transparent parts. To investigate whether consumers could discern the design intentions themselves and to prevent a social desirability bias, we encouraged the 
consumers to express their own opinions, rather than presenting them with the anticipated design intentions. To do so, four questions were planned to encourage consumers to talk more about transparency. These questions were asked in a sequence of prompts from relatively open questions to concrete questions. Table 7 presents the interview questions and objectives of each question.

[Table 7 near here]

\subsection{Data Analysis}

The interviews lasted between 40 and 81 minutes. The 13 consumer interviews were fully transcribed and analysed using Atlas.it. The consumers' opinions related to the overall evaluation of the product examples were excluded from the analysis, as the specific focus of this research was to understand their interpretations of transparency.

Study 2 sought to explore how consumers interpret transparency in product design and whether the design intentions were fulfilled. To assess the fulfilment of design intentions, the results from Study 1 were used as a coding framework to analyse the data from Study 2. Specifically, the consumers' quotes in Study 2 were categorised as belonging to one of the 11 codes and 5 themes representing the design intentions of Study 1 . When the consumers mentioned the look of a product, we assigned these contents to the theme 'enrich visual appeal'. When consumers also mentioned product functionality triggered by the look, we assigned the quote to both 'enrich visual appeal' and 'demonstrate product functionality'.

This procedure was executed by the first author as well as another judge who was unaware of the research goals. Prior to the coding task, the coding scheme was presented to the second judge. The description of each code and examples of the consumers' quotes that 
would fall into each code were also provided. Next, the results of the categorisation were compared with the categorisation made by the first author. Cohen's kappa coefficient was 0.92, suggesting high inter-coder reliability.

\subsection{Results}

In general, the consumer interviews ran smoothly. The participants' opinions of transparency in the stimuli products corresponded highly. The following section presents the results.

\subsubsection{Enrich visual appeal}

The participants interpreted transparency as intended by the designers. Specifically, the participants mentioned several effects, such as that the design looked like an ice cube, a creature in ocean or a crystal, corresponding to the design intention to create special visual effects by transparency. With respect to aesthetic meanings, the participants mentioned different ones, such as fresh, clean and light. The participants also mentioned that transparency was beautiful in general. Furthermore, the participants expressed that for some product designs, the involvement of transparency was novel and unique. Table 8 presents the consumer quotes and the participants who had mentioned this code.

[Table 8 near here]

In Study 1, the designers intended to use transparency to 'improve visual complexity' and make product design aesthetically appealing. Study 2 revealed that the participants felt that transparency was beautiful, but they could not clarify an underlying reason. While the designers' expertise enabled them to explain specific ways to make products look aesthetically appealing, consumers may not be equipped with the necessary 
knowledge. Nevertheless, the consumers did mention that transparency was beautiful; thus, we concluded that the design intention to improve visual complexity was met.

\subsubsection{Enrich product experience}

Corresponding to the design intention 'enrich product experience', the participants reported that transparency allowed them to observe and enjoy the process of using certain products (e.g., coffee dripper and soy milk maker). The participants also reported that transparency created a visual channel for their sensorial experience by appreciating the inside contents, such as seeing ice in the ice-coffee dripper and seeing fire in the stove. Moreover, the participants mentioned that transparency decreased the distance between the product and themselves, which promoted an engaging product experience. Table 9 presents the concrete quotes and the corresponding quotes.

[Table 9 near here]

\subsubsection{Improve product usability}

Regarding the design intention 'improve product usability', the participants mentioned that products with transparency are easy to use. Specifically, the participants mentioned that they can see the operation status of the products through transparency, which allows them to know whether the products work normally. The participants can also learn the present situation, which can provide suggestions for their operation. In addition, the participants can observe the outcomes of the product operation through transparency (see Table 10 for consumers' quotes).

[Figure 7 near here] 
[Table 10 near here]

\subsubsection{Facilitate consumers' comprehension}

Consistent with the design intention 'facilitate consumers' comprehension', the majority of the participants confirmed that they gained better comprehension by seeing the product's working process through the transparent cover (see Table 11 for the consumer quote). This finding indicates that the participants were able to notice the additional information conveyed through transparency and to subsequently process it.

[Table 11 near here]

The participants provided insights on how transparency assisted their comprehension. First, they explained that seeing how the working process was direct and intuitive, which assisted their comprehension. For example, one participant said, 'Because the ActiFryer is new, someone may be confused about how to use air to fry food. Transparency can allow people to directly see how it fries food from raw to cooked using air (P4)'. Second, participants mentioned that their curiosity was satisfied by seeing what was going on underneath the transparent covers of the products. One participant expressed the following: 'The transparent cover allows you to see internal components... People are curious, they want to know what is inside (P10)'. Third, the participants explained that their concerns (e.g., safety) about using the innovative technology can be relieved by seeing the internal components through the transparent cover. One participant offered the following explanation:

'The transparent cover makes me feel relieved. Because it is a fryer that uses a new technology... If it uses [an] opaque cover, as frying requires a very high temperature, I am worried 
that it will explode. I am not sure whether it is safe or not. By using [a] transparent [cover], I feel it is safe, I feel relieved (P2)'.

The product examples that participants reported to understand better because of the transparent parts mainly concerned innovative products, such as the Tefal ActiFryer and Dyson vacuum cleaner. For consumer electronics (e.g., wireless camera [No. 24]), the participants did not report better comprehension. Instead, they felt it was disorganised; as one participant mentioned, 'It is messy inside (P13)'.

\subsubsection{Demonstrate product functionality}

Corresponding to the design intention 'demonstrate product functionality', most of the participants reported that products with transparency performed better. The consumers' quotes were assigned to the code 'demonstrate innovative technology' (see Table 12). No quotes were categorised in the code 'demonstrate updated version of current technology'. We believe that this was caused by the consumers' limited knowledge of the integrated technology in the products. Consequently, consumers were not able to evaluate whether the integrated technology was an innovative technology or merely an updated version of a current technology.

[Table 12 near here]

Moreover, the consumers perceived the products with transparency to have superior functionality for the following two reasons. First, the exposure of the internal components allowed the consumers to assess the quality of the products, as mentioned in the case of the soy milk maker (No. 6) (see Figure 7): 'Look at this circle: there is one more layer under it, so the heating effect must be better. This layer looks solid and heavy, so this must be [a] 
medium or even a better soy milk maker' (P7). Next, the participants considered the usage of transparency as a result of the designer's intentional choice. Subsequently, the participants believed that if the companies/designers dared to expose the internal parts, the product performance must be innovative and effective. One participant mentioned: 'Using transparency in [a] new product suggests that their technological ability is one step forward, because they [manufacturers/designers] dare show new things to you (P10)'.

\subsection{Discussion of Study 2}

Study 2 consisted of consumer interviews to uncover consumers' opinions of transparency in product design. The consumers' opinions were analysed using the coding framework resulting from the designer interviews in Study 1 . The results validated the five design intentions of using transparency. Specifically, for each design intention, the corresponding consumers' quotes were found, suggesting that the consumers interpreted transparency in the ways intended by the designers. In terms of concrete ways to achieve the design intentions, consumer quotes can be found for a majority of the ways. No consumer quotes were assigned to the code demonstrate updated version of current technology. We believe that this is caused by the differences in the design knowledge between the designers and the consumers. Consumers do not have the knowledge to distinguish the differences between an updated version of the current technology and an innovative technology. However, as consumers perceive superior functionality, we still consider the fulfilment of the design intention.

\section{General Discussion}

This research reports two studies to investigate the product feature of transparency in 
product design. Designer interviews in Study 1 provide an overview of the design intentions of using transparency in product design and the specific ways to achieve each design intention (see Table 13). The prominence of these design intentions differs for different product categories and the stage of product lifecycle. This overview is further validated by the consumer interviews in Study 2 .

[Table 13 near here]

\subsection{Theoretical Contributions}

This research contributes to the literature on consumers' interpretations of different product features (e.g., novelty, visual complexity and unity). This line of research has provided knowledge for designers to purposefully manipulate different product features to trigger specific consumers' interpretations, rather than relying heavily on their 'intuitive judgements' and 'educated guesses' (Crilly, Moultrie, and Clarkson 2004). Specifically, this research contributes by investigating the product feature of transparency, which has been used across diverse product categories but remained unexplored thus far. Further, we present a comprehensive overview of the design intentions of using transparency in product design, together with the specific ways to achieve each design intention (see Table 13). The investigation of transparency provides knowledge concerning the effects of presenting additional information on consumers' interpretations of the product. The results revealed that transparency can communicate additional information related to the product's operation process, the working process of products and the internal technical components. Depending on the product category and the product lifecycle stage, the additional information influences consumers' experience, their comprehension of a product's innovative functionality and their perception of product usability and product functionality. 
We acknowledge that these intentions are not exclusively evoked by transparency and other product features can evoke similar design intentions. However, the use of transparency provides designers with an alternative option to fulfil their intentions, and more importantly, it offers a different underlying mechanism by communicating additional information underneath the product covers. For example, past research has demonstrated that by making use of novelty (Mugge and Schoormans 2012a), harmony (Mugge, Dahl, and Schoormans 2017), and visual complexity (Creusen, Veryzer, and Schoormans 2010) in the product appearance, designers can trigger perceptions of advanced technology, leading consumers to believe that the product has superior performance quality, which is related to the design intention 'demonstrate product functionality'. However, transparency demonstrates product functionality in a different way. Specifically, as transparency exposes the product's internal components, consumers are able to assess their quality, which results in perceptions of superior product functionality. These perceptions come from consumers' inferences regarding the reason why designers use transparency. Consumers believe that the product must perform effectively if designers dare to show the components inside.

\subsection{Practical Implications}

This research offers important practical implications for designers for the effective use of transparency in product design. As the choice for transparency will generally result in increased product costs, it is important for designers to clearly articulate this choice to other stakeholders in the product development team. This research provides an overview of the design intentions of using transparency, which can offer actionable and practical information to designers. While holding an intention, designers can be informed whether the intention can be achieved, how to achieve it and how to balance it with other intentions. 
Specifically, while designing, designers face different challenges depending on different contexts, such as product category and product lifecycle. When designing a highly innovative product, designers face the challenge of communicating its innovative functionality (Eisenman 2013). Differently, when introducing a product that is mature in the markets, companies may ask their designers to improve its usability to stand out from competitors. This overview can inform designers whether the hold intention can be achieved by using transparency and the specific ways to fulfil the intention. For example, while designing a kitchen appliance, designers may intend to improve product usability. By utilising this overview, designers can identify ways that transparency can fulfil this intention and the specific ways to achieve it (i.e., the communication of the operative status, the immediate feedback and the operative outcome). Next, depending on the characteristic(s) of the product, designers can think about what information is crucial to the product's usability and decide an optimal way to communicate it.

Moreover, as design intentions are often related to each other, designers may intend to use transparency to fulfil one intention while other intentions can also be covered. This overview can help designers consider the influence of using transparency in product design comprehensively. From the example of designing a kitchen appliance, the designers learnt that the intention enrich product experience could also be covered. In this case, the designers needed to carefully consider whether the way of using transparency could effectively improve product usability and maximise product experience. More importantly, this overview can help designers prevent undesirable situations. In particular, after deciding to use transparency to fulfil the prominent intention, designers can refer to this overview to consider how transparency influences other design intentions and whether there is any undesirable effect. For instance, while designing consumer electronics, designers may 
decide to use transparency for the products' embodiments to demonstrate product functionality. By referring to this overview, designers can know that the use of transparency can also enrich the product's visual appeal and product experience. Using transparency may not influence product usability for consumer electronics, but it can hinder consumers' comprehension as transparency can reveal the internal chips and sensors of consumer electronics. Then, designers can consider how to fulfil the intention demonstrate product functionality while avoiding hindering consumers' comprehension. One possible way could be to use translucent materials to embody products instead of transparent ones. For example, when the first Fairphone was launched, a translucent cover was used. Through the translucent cover, consumers could see the internal components in a blurred manner, which triggered their perception of powerful product functionality but was unlikely to result in confusion.

\subsection{Limitations \& Future Research}

There are different opportunities for future research to strengthen our findings. This research took a qualitative approach to generate an overview of the design intentions of using transparency in product design. For future research, it would be interesting to continue the investigation of transparency through a quantitative method using larger consumer samples. Specifically, future research can investigate the underlying mechanisms of how transparency influences consumers' interpretations. For example, in Study 2, the results revealed three reasons that consumers mentioned for how transparency facilitated their comprehension (i.e., seeing the working process was intuitive, it satisfied their curiosity and gave them a perception of safety). Revealing the underlying mechanisms can contribute to the literature on the influences of product design on consumer responses. 
Moreover, future research can use quantitative methods to compare consumers' interpretations and design intentions for individual stimuli products, resulting in uncovering products where the correspondence rate is relatively high or low. By comparing the products with the high and low correspondence rates, we can learn which ways of using transparency are more effective than others, which can provide further guidance for the successful use of transparency in product design.

Furthermore, we used pictures of products as the stimuli. Yet, it could be interesting to use real products as the stimuli in future research. As transparency communicates additional information while using products, the use of real products as stimuli can deepen our understanding of how transparency influences consumers' operation of a product and long-term experience. It would also be interesting to investigate the use of transparency in other contexts, such as fast-moving consumer goods. It can contribute to the knowledge of the role of transparency in different contexts.

In addition, in this research, experienced designers - professional designers with years of experience - were interviewed. It would be interesting for future research to interview actual designers. Thus, we could learn not only the underlying intentions but also other factors that influence the expression of such intentions. In other words, it could help us understand the potential barriers for the realisation of design intentions in product design. Potentially, this will direct us to new research needs for supporting the realisation of design intentions in product development teams.

\section{Acknowledgements}

We sincerely appreciate the valuable comments from three anonymous reviewers for this article.

\section{Declaration of interest statement}

There are no potential conflict of interest related with this research. 


\section{References}

Ahmed, Saeema, and Per Boelskifte. 2006. "Investigations of product design engineering students intentions and a users perception of product character." NordDesign 2006, Reykjavik, Iceland.

Ashby, M.F., and K. Johnson. 2002. Materials and Design: The Art and Science of Material Selection in Product Design. Oxford: Butterworth-Heinemann.

Barnes, Cathy, and Stephen Paul Lillford. 2009. "Decision support for the design of affective products." Journal of Engineering Design 20 (5):477-492.

Berlyne, Daniel E. 1971. Aesthetics and psychobiology. New York: Appleton-Century-Crofts.

Billeter, Darron, Meng Zhu, and J. Jeffrey Inman. 2012. "Transparent Packaging and Consumer Purchase Decisions " NA-Advances in Consumer Research

Blijlevens, Janneke, Claus-Christian Carbon, Ruth Mugge, and Jan PL Schoormans. 2012. "Aesthetic appraisal of product designs: Independent effects of typicality and arousal." British Journal of Psychology 103 (1):44-57.

Blijlevens, Janneke, Marielle EH Creusen, and Jan PL Schoormans. 2009. "How consumers perceive product appearance; the identification of three product appearance attributes." international Journal of Design 3 (3):27-35.

Bloch, P. H. . 1995. "Seeking the ideal form: Product design and consumer response." The Journal of Marketing:16-29.

Camargo, Fabio R, and Brian Henson. 2015. "Beyond usability: designing for consumers' product experience using Rasch model." Journal of Engineering Design 26 (4-6):121-139.

Chen, Kuohsiang, and Charles L Owen. 1998. "A study of computer-supported formal design." Design Studies 19 (3):331-359.

Coates, Del. 2003. Watches tell more than time. London: McGraw-Hill.

Creusen, and Jan PL Schoormans. 2005. "The different roles of product appearance in consumer choice*." Journal of product innovation management 22 (1):63-81.

Creusen, Robert W Veryzer, and Jan PL Schoormans. 2010. "Product value importance and consumer preference for visual complexity and symmetry." European Journal of Marketing $44(9 / 10): 1437-1452$.

Crilly, Nathan, David Good, Derek Matravers, and P John Clarkson. 2008. "Design as communication: exploring the validity and utility of relating intention to interpretation." Design Studies 29 (5):425-457.

Crilly, Nathan, James Moultrie, and P John Clarkson. 2004. "Seeing things: consumer response to the visual domain in product design." Design studies 25 (6):547-577.

Crilly, Nathan, James Moultrie, and P John Clarkson. 2009. "Shaping things: intended consumer response and the other determinants of product form." Design Studies 30 (3):224-254.

Da Silva, Odette, Nathan Crilly, and Paul Hekkert. 2015. "How people's appreciation of products is affected by their knowledge of the designers' intentions." International Journal of Design 9 (2):21-33.

Dell'Era, Claudio, Tommaso Buganza, Camilla Fecchio, and Roberto Verganti. 2011. "Language Brokering: stimulating creativity during the concept development phase." Creativity and Innovation Management 20 (1):36-48.

Deng, Xiaoyan, and Raji Srinivasan. 2013. "When do transparent packages increase (or decrease) food consumption?" Journal of Marketing 77 (4):104-117.

Desmet, P.M.A., and P. Hekkert. 2007. "Framework of product experience." International Journal of Design 1 (1):57-66.

Desmet, P.M.A., Juan Carlos Ortiz Nicolas, and Jan Schoormans. 2008. "Product personality in physical interaction." Design Studies 29 (5):458-477.

Eisenman, Micki. 2013. "Understanding aesthetic innovation in the context of technological evolution." Academy of Management Review 38 (3):332-351. 
Fernqvist, Fredrik, Annika Olsson, and Sara Spendrup. 2015. "What's in it for me? Food packaging and consumer responses, a focus group study " British Food Journal 117 (3):1122-1135.

Garcia, Rosanna, and Roger Calantone. 2002. "A critical look at technological innovation typology and innovativeness terminology: a literature review." Journal of product innovation management 19 (2):110-132.

Giannini, Franca, Marina Monti, and Gerd Podehl. 2006. "Aesthetic-driven tools for industrial design." journal of Engineering Design 17 (3):193-215.

Handel, S., and S. Imai. 1972. "The free classification of analyzable and unanalyzable stimuli." Attention, Perception, \& Psychophysics 12 (1):108-116.

Hekkert, Paul, D. Snelders, and PCW. Wieringen. 2003. "'Most advanced, yet acceptable': typicality and novelty as joint predictors of aesthetic preference in industrial design." British Journal of Psychology 94 (1):111-124.

Hsiao, Shih Wen, and Hsi Ping Wang. 1998. "Applying the semantic transformation method to product form design." Design Studies 19 (3):309-330.

Hsu, Shang H, Ming C Chuang, and Chien C Chang. 2000. "A semantic differential study of designers' and users' product form perception." International Journal of Industrial Ergonomics 25 (4):375-391.

Jordan, P. W. 1998. An introduction to usability. London: Taylor and Francis.

Karana, Elvin, Bahar Barati, Valentina Rognoli, and Anouk Zeeuw van der Laan. 2015. "Material Driven Design (MDD): A Method to Design for Material Experiences." International Journal of Design 9 (2):35-54.

Karana, Elvin, Paul Hekkert, and Prabhu Kandachar. 2008. "Material considerations in product design: A survey on crucial material aspects used by product designers." Materials \& Design 29 (6):1081-1089.

Karana, Elvin, Paul Hekkert, and Prabhu Kandachar. 2009. "Meanings of materials through sensorial properties and manufacturing processes." Materials \& Design 30 (7):2778-2784.

Kesteren, Ilse van, Sjef de Bruijn, and Pieter Jan Stappers. 2008. "Evaluation of materials selection activities in user-centred design projects." Journal of Engineering Design 19 (5):417-429.

Kumar, Minu, and Nitika Garg. 2010. "Aesthetic principles and cognitive emotion appraisals: How much of the beauty lies in the eye of the beholder?" Journal of Consumer Psychology 20 (4):485-494.

Lee, Jeongmin, Bohee Jung, and Wujin Chu. 2015. "Signaling environmental altruism through design: The role of green cue prominence in hybrid cars." International Journal of Design 9 (2):79-91.

Lockton, Dan, David Harrison, and Neville A Stanton. 2010. Design with intent: 101 patterns for influencing behaviour through design. Windsor: Equifine.

Mugge, Ruth. 2011. "The effect of a business-like personality on the perceived performance quality of products." International Journal of Design, 5 (3), 2011.

Mugge, Ruth, Dahl, and J. P. Schoormans. 2017. "“What You See, Is What You Get?" Guidelines for Influencing Consumers' Perceptions of Consumer Durables through Product Appearance. ." Journal of Product Innovation Management In Press.

Mugge, Ruth, P.C. Govers, and Jan Schoormans. 2009. "The development and testing of a product personality scale." Design Studies 30 (3):287-302

Mugge, Ruth, and Jan PL Schoormans. 2012a. "Newer is better! The influence of a novel appearance on the perceived performance quality of products." Journal of Engineering Design 23 (6):469-484.

Mugge, Ruth, and Jan PL Schoormans. 2012b. "Product design and apparent usability. The influence of novelty in product appearance." Applied ergonomics 43 (6):1081-1088.

Person, Oscar, and Dirk Snelders. 2010. "Brand styles in commercial design." Design Issues 26 (1):82-94. 
Post, R. A. G., Janneke Blijlevens, and P Hekkert. 2016. "'To preserve unity while almost allowing for chaos': Testing the aesthetic principle of unity-in-variety in product design." Acta Psychologica 163:142-152.

Simmonds, G., and C. Spence. 2017. "Thinking inside the box: How seeing products on, or through, the packaging influences consumer perceptions and purchase behaviour. Food Quality and Preference, 62, 340-351." Food Quality and Preference 62:340-351.

Simmonds, G., A. T. Woods, and C. Spence. 2018. "Show me the goods': Assessing the effectiveness of transparent packaging vs. product imagery on product evaluation." Food Quality and Preference 63:18-27.

Smets, GJF, and CJ Overbeeke. 1995. "Expressing tastes in packages." Design Studies 16 (3):349365.

Thomas, David R. 2006. "A general inductive approach for analyzing qualitative evaluation data." American Journal of Evaluation 27 (2):237-246.

Veryzer, Robert W, and J Wesley Hutchinson. 1998. "The influence of unity and prototypicality on aesthetic responses to new product designs." Journal of consumer research 24 (4):374-385. 


\section{Appendixes}

\section{Appendix A. Stimuli product used in study 1 and study 2}

All the stimuli were used in study 1 . The following stimuli were used in study $2: 4,6,9,10,11,12$, $13,16,18,19,20,22,24,25,31,32$. The whole set of stimuli product images is available on request.

\begin{tabular}{|c|c|c|}
\hline & Product Examples & Source \\
\hline 1 & $\begin{array}{l}\text { Concept design of future } \\
\text { smart phone }\end{array}$ & $\begin{array}{l}\text { http://www.yankodesign.com/2009/08/18/phone-that- } \\
\text { shames-the-weather-bureau/ }\end{array}$ \\
\hline 2 & Concept design of air cleaner & https://www.behance.net/gallery/17624391/Air-Purifier- \\
\hline 3 & $\begin{array}{l}\text { Concept design of USB } \\
\text { memory stick }\end{array}$ & $\begin{array}{l}\text { http://www.tuvie.com/funny-usb-memory-stick-features- } \\
\text { different-colored-lights-for-different-state/ }\end{array}$ \\
\hline 4 & Essential oil diffuser & http://zaq.com/dew/ \\
\hline 5 & $\begin{array}{l}\text { IRON 725: Concept design of } \\
\text { iron } \\
\end{array}$ & https://ifworlddesignguide.com/entry/39195-b-iron-725 \\
\hline 6 & Deer DR-021: soy milk maker & http://www.goodjd.com/product/p-7894.html \\
\hline 7 & $\begin{array}{l}\text { Konstruktor transparent } \\
\text { collector's edition Lomo } \\
\text { camera (display only) }\end{array}$ & http://shop.lomography.com/en/konstruktor-transparent \\
\hline 8 & Wireless game controller & $\begin{array}{c}\text { https://www.tmart.com/2-4GHz-PC-PS2-Controller-with- } \\
\text { Receiver-Blue-Transparent p285986.html }\end{array}$ \\
\hline 9 & $\begin{array}{l}\text { NiZHi TT-028: mini digital } \\
\text { portable speaker }\end{array}$ & http://www.usb300.com/china/productinfo.asp?id=230 \\
\hline 10 & $\begin{array}{l}\text { In Win TOU aluminium } \\
\text { frame PC chassis }\end{array}$ & http://www.techspot.com/review/794-in-win-tou/ \\
\hline 11 & $\begin{array}{l}\text { Philips FC6130: handheld } \\
\text { vacuum cleaner }\end{array}$ & $\begin{array}{c}\text { http://www.philips.co.in/c-p/FC6130_01/minivac-handheld- } \\
\text { vacuum-cleaner }\end{array}$ \\
\hline 12 & $\begin{array}{l}\text { Dyson DC 58: handheld } \\
\text { vacuum cleaner }\end{array}$ & http://www.dyson.co.uk/vacuum-cleaners/handheld.aspx \\
\hline 13 & $\begin{array}{l}\text { Vicks V750: warm mist } \\
\text { humidifier }\end{array}$ & $\begin{array}{c}\text { http://vicks.com/en-us/shop-products/humidifiers-steam- } \\
\text { inhalers/v750-warm-mist-humidifier }\end{array}$ \\
\hline 14 & Dyson humidifier & http://www.dyson.com/air-treatment/humidifiers.aspx \\
\hline 15 & Concept design of tablet & $\begin{array}{c}\text { http://www.gizmocrazed.com/2013/02/this-stunning-ipad- } \\
\text { concept-features-an-all-transparent-body/ }\end{array}$ \\
\hline 16 & Concept design of television & $\begin{array}{c}\text { http://www.yankodesign.com/2011/02/03/look-carefully- } \\
\text { it } \% \text { E2\%80\%99s-a-transparent-tv/ }\end{array}$ \\
\hline 17 & $\begin{array}{l}\text { Electrolux Green AC: } \\
\text { concept design of air } \\
\text { conditioner }\end{array}$ & $\begin{array}{l}\text { https://www.behance.net/gallery/1157281/Green-AC- } \\
\text { Electrolux }\end{array}$ \\
\hline 18 & $\begin{array}{l}\text { Dyson CR01 memory silver: } \\
\text { washing machine }\end{array}$ & http://www.dyson.co.uk/support/cr01/cro1-memory-silver \\
\hline 19 & $\begin{array}{l}\text { Breville Crystal Clear: } \\
\text { electrical kettle }\end{array}$ & https://www.breville.com/us/en/products/tea/bke595.html \\
\hline 20 & $\begin{array}{c}\text { Hase Asmara stove } \\
\text { Hase Kaminofenbau Germany }\end{array}$ & http://www.boudrie-kachels-haarden.nl/hase-asmara.html \\
\hline 21 & Magimix vision toaster & $\begin{array}{c}\text { http://www.magimix.com/usa- } \\
\text { canada/products/BREAKFAST/Toaster/Vision-Toaster/ }\end{array}$ \\
\hline 22 & $\begin{array}{l}\text { Tefal ActiFry Family } \\
\text { AH900233 }\end{array}$ & $\begin{array}{c}\text { http://www.tefal.com/Cooking- } \\
\text { appliances/Fryers/ActiFry/ActiFry-Family/p/1500635312 }\end{array}$ \\
\hline 23 & $\begin{array}{l}\text { Apple Mac G3: personal } \\
\text { computer displayer }\end{array}$ & $\begin{array}{c}\text { https://www.macworld.com/article/1135017/macs/imacanniv } \\
\text { ersary.html }\end{array}$ \\
\hline 24 & OZAKI O!care wireless & http://ozakiverse.com/products/others/ocare \\
\hline
\end{tabular}




\begin{tabular}{|c|c|c|}
\hline & camera & \\
\hline 25 & $\begin{array}{l}\text { Biduhaev cold brew system } \\
\text { coffee dripper }\end{array}$ & http://www.biduhaev.com/ \\
\hline 26 & $\begin{array}{l}\text { Stylepie EVE lonizer power } \\
\text { bank }\end{array}$ & $\begin{array}{c}\text { http://www.stylepie.com/zh/product/eve } \% \text { E8\%B4\%9F\%E7 } \\
\% \text { A6\%BB\%E5\%AD\%90\%E7\%A9\%BA\%E6\%B0\%94\%5 } \\
\% 87 \% 80 \% \text { E5\%8C\%96\%E5\%99\%A8/ }\end{array}$ \\
\hline 27 & Lexon Flow FM radio & http://www.lexon-design.com/la94b5-flow-bleu.html \\
\hline 28 & $\begin{array}{l}\text { kMix KMX51G Kenwood } \\
\text { kitchen machine }\end{array}$ & $\begin{array}{l}\text { https://www.kenwoodworld.com/en/kenwoodproducts/prepa } \\
\text { re-and-bake/kitchen-machines/other-kitchen- } \\
\text { machines/kmx750rd?sku=0W20011138 }\end{array}$ \\
\hline 29 & $\begin{array}{l}\text { Philips grind and brew coffee } \\
\text { maker }\end{array}$ & $\begin{array}{c}\text { http://www.philips.nl/c-p/HD7765_00/grind-brew- } \\
\text { koffiezetapparaat }\end{array}$ \\
\hline 30 & $\begin{array}{l}\text { Harman Kardon SoundSticks } \\
\text { III }\end{array}$ & $\begin{array}{l}\text { http://www.harmankardon.com/computer- } \\
\text { speakers/SOUNDSTICKS+III.html }\end{array}$ \\
\hline 31 & Philips SalonDry hairdryer & http://www.philips.co.in/c-p/HP4940 00/salondry-hairdryer \\
\hline 32 & $\begin{array}{l}\text { Philips LivingColors } \\
\text { Generation } 2\end{array}$ & $\begin{array}{c}\text { https://www.philips.com.hk/en/c-p/691436086/livingcolors- } \\
\text { gen2-clear }\end{array}$ \\
\hline
\end{tabular}

\section{Appendix B. Results of additional analyses for study 1}

Table for results of content analyses for identifying design intentions from marketing materials and the correspondences between design intentions found from designer interviews.

\begin{tabular}{|c|c|c|c|}
\hline $\begin{array}{c}\text { Product } \\
\text { Examples }\end{array}$ & $\begin{array}{l}\text { Selected product descriptions related } \\
\text { with design intentions of using } \\
\text { transparency }\end{array}$ & $\begin{array}{l}\text { Identified Design } \\
\text { Intentions }\end{array}$ & $\begin{array}{c}\text { Corresponding Design } \\
\text { Intentions found from } \\
\text { Designer Interviews }\end{array}$ \\
\hline $\begin{array}{l}\text { No.2. Concept } \\
\text { design of air } \\
\text { cleaner }\end{array}$ & $\begin{array}{l}\text { A very iconic transparent screen to show } \\
\text { the lighting and information. Intuitive } \\
\text { experience. }\end{array}$ & $\begin{array}{l}\text { Novel style. } \\
\text { Enrich product } \\
\text { experience }\end{array}$ & $\begin{array}{l}\text { Introduce a novel style. } \\
\text { Enrich product } \\
\text { experience }\end{array}$ \\
\hline $\begin{array}{l}\text { No.3. Concept } \\
\text { design of USB } \\
\text { memory stick }\end{array}$ & $\begin{array}{l}\text { It would be more fun if the lights can } \\
\text { move in the glass when you shake it. }\end{array}$ & $\begin{array}{l}\text { Create a new } \\
\text { experience by } \\
\text { allowing } \\
\text { consumers to see } \\
\text { the lights inside }\end{array}$ & $\begin{array}{c}\text { Enrich consumers' } \\
\text { sensory experience by } \\
\text { appreciating the inside } \\
\text { content }\end{array}$ \\
\hline $\begin{array}{l}\text { No.4. Essential } \\
\text { oil diffuser }\end{array}$ & $\begin{array}{l}\text { Dew brings the freshness ... into your } \\
\text { everyday life. }\end{array}$ & $\begin{array}{l}\text { Communicate the } \\
\text { meaning of } \\
\text { Freshness }\end{array}$ & $\begin{array}{l}\text { Trigger certain aesthetic } \\
\text { meanings }\end{array}$ \\
\hline $\begin{array}{l}\text { No.7. Konstruk } \\
\text { tor transparent } \\
\text { collector's } \\
\text { edition Lomo } \\
\text { camera } \\
\text { (display only) }\end{array}$ & $\begin{array}{l}\text { Konstruktor Transparent Collector's } \\
\text { Edition lets you discover the magic inside. }\end{array}$ & $\begin{array}{l}\text { Allow consumers } \\
\text { to see inside } \\
\text { contents }\end{array}$ & $\begin{array}{l}\text { Enrich consumers' } \\
\text { sensory experience by } \\
\text { appreciating the inside } \\
\text { content }\end{array}$ \\
\hline $\begin{array}{l}\text { No.9. mini } \\
\text { digital portable } \\
\text { speaker }\end{array}$ & $\begin{array}{l}\text { Elegant and stylish in appearance, compact } \\
\text { and portable. With unique transparent } \\
\text { acrylic design and colorful lighting } \\
\text { function, making it more fascinating! }\end{array}$ & Unique style & Introduce a novel style \\
\hline $\begin{array}{l}\text { No.10. In Win } \\
\text { TOU } \\
\text { aluminium } \\
\text { frame PC } \\
\text { chassis }\end{array}$ & $\begin{array}{l}\text { When illuminated from the inside with } \\
\text { your system on, the tòu's mirror coating } \\
\text { becomes transparent, showing off your } \\
\text { internal hardware and hopefully reassuring } \\
\text { your } \$ 800 \text { purchase. }\end{array}$ & $\begin{array}{l}\text { Demonstrate } \\
\text { technology }\end{array}$ & $\begin{array}{c}\text { Demonstrate innovative } \\
\text { technology }\end{array}$ \\
\hline $\begin{array}{l}\text { No.15. } \\
\text { Concept }\end{array}$ & $\begin{array}{l}\text { Sometimes, however, once comes across } \\
\text { our desks that catches our eye. }\end{array}$ & le & yle \\
\hline
\end{tabular}




\begin{tabular}{|c|c|c|c|}
\hline design of tablet & & & \\
\hline $\begin{array}{l}\text { No.16.Concept } \\
\text { design of } \\
\text { television }\end{array}$ & $\begin{array}{l}\text { As the first of its kind, the Loewe Invisio } \\
\text { introduces technical innovation, combining } \\
\text { conventional LCD and the latest TOLED } \\
\text { display technology. }\end{array}$ & $\begin{array}{l}\text { Demonstrate } \\
\text { technology. }\end{array}$ & $\begin{array}{c}\text { Demonstrate innovative } \\
\text { technology }\end{array}$ \\
\hline $\begin{array}{l}\text { No.17. } \\
\text { concept design } \\
\text { of air } \\
\text { conditioner }\end{array}$ & $\begin{array}{l}\text { The louvers were made in transparent and } \\
\text { frosted plastic which gives the impression } \\
\text { of clean and fresh air. }\end{array}$ & $\begin{array}{l}\text { Communicate the } \\
\text { meaning of } \\
\text { cleanness and } \\
\text { freshness. }\end{array}$ & $\begin{array}{l}\text { Trigger certain aesthetic } \\
\text { meanings }\end{array}$ \\
\hline $\begin{array}{c}\text { No.19. } \\
\text { electrical kettle }\end{array}$ & $\begin{array}{l}\text { A clean taste starts with clean water. How } \\
\text { do you ensure a more pure boil? With the } \\
\text { natural purity of glass -- easy to see, easy } \\
\text { to clean. So simply elegant, you may want } \\
\text { to watch water boil. }\end{array}$ & $\begin{array}{l}\text { Communicate the } \\
\text { meaning of purity. } \\
\text { Allow consumers } \\
\text { to see the process. }\end{array}$ & $\begin{array}{l}\text { Trigger certain aesthetic } \\
\text { meanings. } \\
\text { Enrich consumers' } \\
\text { sensorial experience by } \\
\text { appreciating the process } \\
\end{array}$ \\
\hline $\begin{array}{l}\text { No.20. Hase } \\
\text { Asmara stove }\end{array}$ & $\begin{array}{l}\text { Hase Asmara woodstove offers beautiful } \\
\text { view of the fire from } 3 \text { sides and with its } \\
\text { high slim shape a leading design. }\end{array}$ & $\begin{array}{l}\text { Reveal view of } \\
\text { fire }\end{array}$ & $\begin{array}{c}\text { Enrich consumers' } \\
\text { sensorial experience by } \\
\text { appreciating the inside } \\
\text { content }\end{array}$ \\
\hline $\begin{array}{l}\text { No.21.Magimi } \\
\text { x vision toaster }\end{array}$ & $\begin{array}{l}\text { The world's first see-through toaster. For } \\
\text { toast, just the way you like it. Visual } \\
\text { control, easy to use, long-life quartz } \\
\text { elements, double insulated. }\end{array}$ & $\begin{array}{l}\text { Communicate } \\
\text { immediate } \\
\text { information. }\end{array}$ & $\begin{array}{l}\text { Provide immediate } \\
\text { feedback }\end{array}$ \\
\hline $\begin{array}{l}\text { No.23. Apple } \\
\text { Mac G3: } \\
\text { personal } \\
\text { computer } \\
\text { displayer } \\
\end{array}$ & $\begin{array}{l}\text { It's hard to beat Apple when it comes to } \\
\text { recognisable products and the } 1998 \text { iMac } \\
\text { is no exception. This all-in-one monitor } \\
\text { and computer has the same visual impact } \\
\text { today as it did then. }\end{array}$ & Novel style & Introduce a novel style \\
\hline $\begin{array}{c}\text { No.25. } \\
\text { Biduhaev cold } \\
\text { brew system } \\
\text { coffee dripper }\end{array}$ & This is an extreme simple product. & $\begin{array}{l}\text { Communicate the } \\
\text { meaning of } \\
\text { simplicity }\end{array}$ & $\begin{array}{l}\text { Trigger certain aesthetic } \\
\text { meanings }\end{array}$ \\
\hline $\begin{array}{l}\text { No.27. Lexon } \\
\text { Flow FM radio }\end{array}$ & $\begin{array}{l}\text { The main goal in creating Flow was to } \\
\text { design a minimalistic radio, limiting the } \\
\text { design to the strict minimum. The idea was } \\
\text { to offer the user the possibility to discover } \\
\text { and understand the industrial design of the } \\
\text { object by allowing, with the transparent } \\
\text { casing, to see inside and see the composing } \\
\text { elements }\end{array}$ & $\begin{array}{l}\text { Minimalistic. } \\
\text { Allow consumers } \\
\text { to see inside } \\
\text { contents. }\end{array}$ & $\begin{array}{l}\text { Trigger certain aesthetic } \\
\text { meanings } \\
\text { Enrich consumers' } \\
\text { sensorial experience by } \\
\text { appreciating the inside } \\
\text { content }\end{array}$ \\
\hline $\begin{array}{c}\text { No.30. } \\
\text { Harman } \\
\text { Kardon } \\
\text { SoundSticks } \\
\text { III } \\
\end{array}$ & $\begin{array}{l}\text { Improving on its famous sibling's pop- } \\
\text { culture appeal, the SoundSticks III system } \\
\text { is all that and much more. }\end{array}$ & Novel style & Introduce a novel style \\
\hline
\end{tabular}




\section{Tables}

Table 1. Detailed information of participants in Study 1

\begin{tabular}{|c|c|c|c|}
\hline & $\begin{array}{l}\text { Work } \\
\text { experience }\end{array}$ & Expertise & Clients/employers \\
\hline $\begin{array}{l}\text { Participant } 1 \\
(\mathrm{P} 1)\end{array}$ & $19 \mathrm{yrs}$ & $\begin{array}{l}\text { Consumer electronics, } \\
\text { automotive }\end{array}$ & $\begin{array}{l}\text { General Motors, Ford Motor, } \\
\text { Philips Design, TCL, Tonly } \\
\text { Electronics, etc. }\end{array}$ \\
\hline Participant 2 & $23 \mathrm{yrs}$ & $\begin{array}{l}\text { Furniture, home } \\
\text { appliances, graphic } \\
\text { design (promotions) }\end{array}$ & Siemens, Cassina, etc. \\
\hline Participant 3 & $27 \mathrm{yrs}$ & $\begin{array}{l}\text { Consumer electronics, } \\
\text { home appliances, } \\
\text { furniture. }\end{array}$ & $\begin{array}{l}\text { Philips, HP, Alessi, Huawei, } \\
\text { Suzuki, Samsung, etc. }\end{array}$ \\
\hline Participant 4 & $18 \mathrm{yrs}$ & $\begin{array}{l}\text { Furniture, household } \\
\text { products, medical } \\
\text { devices, consumer } \\
\text { electronics. }\end{array}$ & $\begin{array}{l}\text { Mercedes-Benz, Hansen, Grohe, } \\
\text { etc. }\end{array}$ \\
\hline Participant 5 & $13 \mathrm{yrs}$ & $\begin{array}{l}\text { Furniture, } \\
\text { transportation, home } \\
\text { appliances, consumer } \\
\text { electronics }\end{array}$ & Coolpad, ZTE, etc. \\
\hline Participant 6 & $12 \mathrm{yrs}$ & $\begin{array}{l}\text { Consumer electronics, } \\
\text { home appliances, } \\
\text { medical devices }\end{array}$ & Electrolux, Philips, Shell, etc. \\
\hline
\end{tabular}


Table 2. Codes and quotes for the design intention 'enrich visual appeal' by using transparency in product design

Code: Create special visual effects (mentioned by P1, P2, P3, P5, P6)

Corresponding quote: 'I have to say that if you have an image of the ice cube light, it directly mimics ice by using a transparent, very thick material, it looks like a box inside an ice cube (P5)'. (See Figure la)

Code: Trigger certain aesthetic meanings (mentioned by P1, P2, P3, P5, P6)

Corresponding quote: 'Imagine, if this part uses the same material as this part... then it would be heavier and look heavy for a portable handheld device. (I think designers added a transparent material) to make the product lighter (P1)'. (See Figure 1b)

Code: Improve visual complexity (mentioned by P2, P3, P4)

Corresponding quote: 'This one uses transparency to break the monolithic look. Because if it is monolithic without any transparency, it is entirely white. It may not look good... To break [the] monolithic look... they used some transparent material to make it beautiful (P4)'. (See Figure 1c)

Code: Introduce a novel style (mentioned by P2, P3)

Corresponding quote: 'I think it just looks cool... I think the intention is just to create it... because you have never seen a speaker that is completely transparent before. So it just looks cool. Especially at that time, because nobody has seen that before (P2)'. (See Figure 1d) 
Table 3. Codes and quotes for the design intention 'enrich product experience'

Code: Enrich consumers' sensorial experience by appreciating the process (mentioned by P1, P3, P5)

Corresponding quote: 'Some designers like to highlight the process... For instance, the coffee dripper-in the old days we didn't see its internal parts and even the working process of coffee machines, it was like a black box. Ultimately, the goal of this range product is for you to enjoy the process (P3)'. (See Figure 2a)

Code: Enrich consumers' sensorial experience by appreciating the inside contents (mentioned by P3, P5, P6)

Corresponding quote: 'They show the nature of the product itself. You know some products related to power, to air, to greenness, to warmth, the relations need to be seen... These are more about the meaning of the products themselves (P5)'. (See Figure 2b)

Code: Enrich consumers' sensorial experience by decreasing the psychological distance between products and consumers (mentioned by P1, P3, P5, P6)

Corresponding quote: 'A transparent block, what everything inside is totally visible. You become part of it. Inviting (P6) (See Figure 2c).' 
Table 4. Codes and quotes for the design intention 'improve product usability'

Code: Communicate operation status (mentioned by P1, P3, P4, P5, P6)

Corresponding quote: 'It tells you that "I am working, I am implementing the process" (P4)'. (See Figure 3a)

Code: Provide immediate feedback (mentioned by P1, P2, P3, P4, P5, P6)

Corresponding quote: 'You get information. When you iron, you may get some wrinkles. If you iron again, it makes it even worse. With this product, you can improve the ironing process. You have better control over the whole process (P5)'. (See Figure 3b)

Code: Show operative outcome (mentioned by P1, P2, P3, P5)

Corresponding quote: 'We need users to see through what is being operated... Transparency has a single function, showing the result of the operation (P3)'. (See Figure 3c) 
Table 5. Code and quote for the design intention 'facilitate consumers' comprehension' Code: Facilitate consumers' comprehension (mentioned by P2, P3, P4, P5, P6)

Corresponding quote: 'By looking at this area, you know what is happening inside... The dust is collected here... We can say that to some extent, by seeing it, users can understand (P4) (see Figure 4)' 
Table 6. Codes and quotes for the design intention 'demonstrate product functionality' Code: Demonstrate innovative technology (mentioned by P1, P2, P3, P4, P5, P6)

Corresponding quote: 'Ultraviolet light to kill bacteria, especially bacteria in the water. Can you see the ultraviolet light? Some new technology has been applied... The product highlights this new technology (No. 14; P5)'. (See Figure 5a)

Code: Demonstrate updated version of current technology (mentioned by P4, P5)

Corresponding quote: '[They] try to show some novelty. They try to show their technology, but actually transparency doesn't really have a functionality here (P5)'. (See Figure 5b) 
Table 7. Interview questions for consumer interviews in Study 2

\begin{tabular}{|c|c|}
\hline \multicolumn{2}{|l|}{ Part 1} \\
\hline Q1 & How do you feel about this product in general? \\
\hline Aim of Q1 & $\begin{array}{l}\text { Familiarise participants with the stimuli products. The product functions } \\
\text { can be explained in detail, when necessary. }\end{array}$ \\
\hline Q2 & What do you think about the design of this product? \\
\hline Aim of Q2 & Encourage participants to focus on product design. \\
\hline \multicolumn{2}{|l|}{ Part 2} \\
\hline Q3 & How do you feel about the transparent parts in this product? \\
\hline Aim of Q3 & $\begin{array}{l}\text { Lead participants to focus on the transparent parts. Learn how participants } \\
\text { respond to transparency. }\end{array}$ \\
\hline \multirow[t]{3}{*}{ Q4 } & Why do you have such feelings? \\
\hline & $\begin{array}{l}\text { Probe: Could you think of several pros and cons of involving transparent } \\
\text { parts in this product? }\end{array}$ \\
\hline & Probe: Why do you think designers use a transparent part here? \\
\hline Aim of Q4 & Trigger consumers to talk more about transparent parts. \\
\hline $\begin{array}{l}\text { Aim of } \\
\text { probe }\end{array}$ & $\begin{array}{l}\text { Encourage participants to search for reasons why transparency contributes } \\
\text { to their specific feelings. }\end{array}$ \\
\hline
\end{tabular}


Table 8. Consumer quotes corresponding to each code for the design intention 'enrich visual appeal'

Code: Create special visual effects (mentioned by P1, P2, P4, P5, P7, P12, P13)

Corresponding quote: 'This product makes me think of an ice cube. Making a speaker look like an ice cube is cool (P2)'. (Portable speaker. No.9)

Code: Trigger certain aesthetic meanings (mentioned by P1, P2, P3, P4, P5, P6, P7, P9, P10, P11, P12, P13)

Corresponding quote: 'This transparent part makes me feel that the product is not that heavy (P1)’. (Hair dryer.No.31)

Code: Improve visual complexity (mentioned by P1, P2, P3, P6, P7, P9, P10, P11, P12, P13)

Corresponding quote: 'I feel that transparent things are pretty $(P 1)$ '. (Chassis PC. No. 10)

Code: Introduce a novel style (mentioned by P1, P3, P5, P6, P7, P11, P12)

Corresponding quote: 'This one is different from other [kettles]. Others are made from ceramics or metal... (P1)’. (Kettle, No. 19) 
Table 9. Consumer quotes corresponding to each code for the design intention 'enrich product experience'

Code: Enrich consumers' sensorial experience by appreciating the process (mentioned by P1, P2, P4, P5, P7, P10, P14)

Corresponding quote: 'I feel this shows the process of making coffee, to see how coffee is made... It is very enjoyable (P7)'. (Coffee dripper. No. 25)

Code: Enrich consumers' sensorial experience by appreciating the inside contents (mentioned by P2, P4, P5, P6, P7, P9, P10, P11)

Corresponding quote: 'Through the transparent cover, we can directly see the fire in the stove. It feels warm. As a stove is used for heating... in a sense, seeing the fire inside feels warm (P4)'. (Stove.No.20)

Code: Enrich consumers' sensorial experience by decreasing the psychological distance between products and consumers (mentioned by P1, P2, P5, P7, P9, P11)

Corresponding quote: 'For the ordinary hair dryers, I turn it on and it blows hot air ... [For this hairdryer] transparency creates a sense of engagement. I can feel something is spinning inside and hot air coming out from here (the transparent part), which makes me feel closer to it (P2).' (Hair dryer. No. 31) 
Table 10. Consumer quotes corresponding to each code for the design intention 'improve product usability'

Code: Communicate operation status (mentioned by P2, P6, P8)

Corresponding quote: 'Many washing machine doors are transparent. You can see how it washes, whether it is spinning, whether it performs well. This is reminding information. For instance, if I press the on button but it does not start working, then I know it is broken or something is wrong (P2)'. (Washing machine. No.18)

Code: Provide immediate feedback (mentioned by P1, P2, P6, P7, P8, P9, P10, P11, P12, P13)

Corresponding quote: 'The transparent one is good... If soy milk is too heavy, you can immediately turn it off. You can always observe the immediate situation inside (See Figure 7. No.6) (P7)'.

Code: Show operative outcome (mentioned by P1, P2, P4, P5, P6, P7, P9, P10, P11, P12, P13)

Corresponding quote: 'It sucks dust into the box. How much dust is collected can be seen easily (P4)'. (Vacuum cleaner. No. 11) 
Table 11. Consumer quote corresponding to the code facilitate consumers' comprehension Code: Facilitate consumers' comprehension (mentioned by P1, P2, P3, P4, P5, P6, P7, P9, P10, P11, P12)

Corresponding quote: 'It [No. 22] (see Figure 4) helps me understand the function, to some degree. It is very intuitive... If [a] salesman introduces this product to me, I understand it as soon as I see it'(P10). 
Table 12. Consumer quotes corresponding to the theme demonstrate product functionality Code: Demonstrate innovative technology (mentioned by P1, P2, P4, P5, P6, P7, P10, P11, P12)

Corresponding quote: 'I can see the internal components. They look elaborated. I think it (No.9) should be a high-end product.'(P10) 
Table 13. Overview of design intentions to use transparency in product design

\begin{tabular}{ll}
\hline $\begin{array}{l}\text { Design } \\
\text { intentions }\end{array}$ & Specific ways to achieve each design intention \\
\hline Enrich visual appeal & \\
& Create special visual effects \\
& Trigger certain aesthetic meanings \\
& Improve visual complexity \\
& Introduce a novel style \\
\hline
\end{tabular}

Enrich product experience

Enrich consumers' sensorial experience by appreciating the process

Enrich consumers' sensorial experience by appreciating the inside content

Enrich consumers' sensorial experience by decreasing the psychological distance between products and consumers

Improve product usability

Communicate operation status

Provide immediate feedback

Show the operative outcome

Facilitate consumers' comprehension

Demonstrate product functionality

Demonstrate updated version of current technology

Demonstrate innovative technology 


\section{Figures}

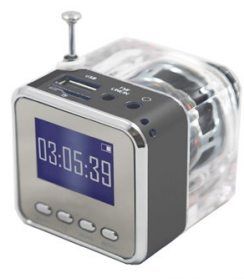

(a)

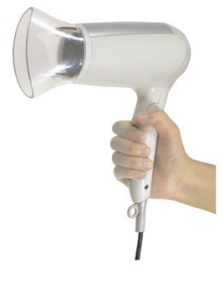

(b)

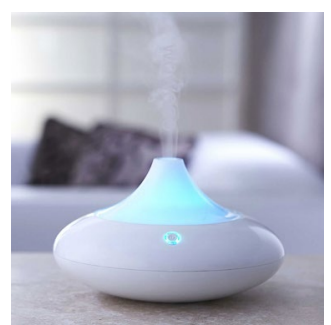

(c)
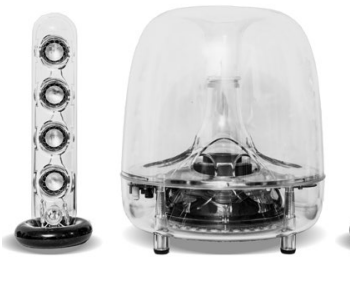

(d)

Figure 1. Product examples that fulfill the design intention 'enrich visual appeal': (a) a portable speaker, product example No. 9; (b) a hairdryer, product example No. 8; (c) an oil diffuser, product example No. 4; (d) a sound, product example No. 30.

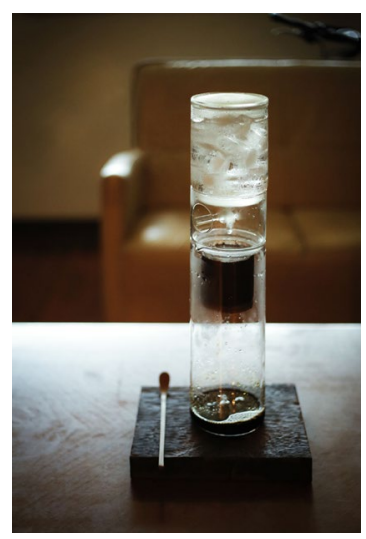

(a)

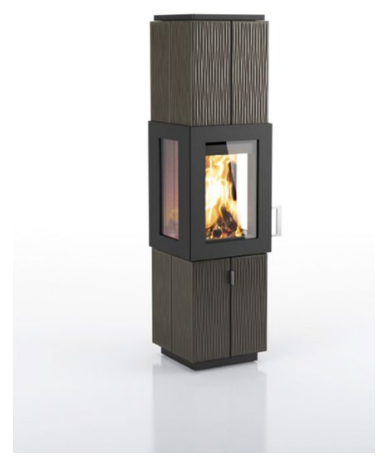

(b)

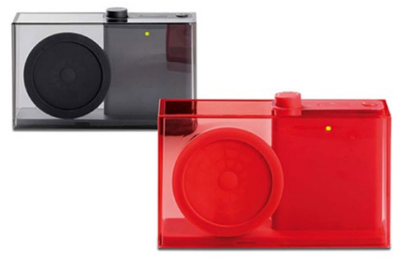

(c)

Figure 2. Product examples that fulfill the design intention 'enrich product experience': (a) a coffee dripper, product example No. 25; (b) a stove, product example No. 20; (c) a radio, product example No. 27. 


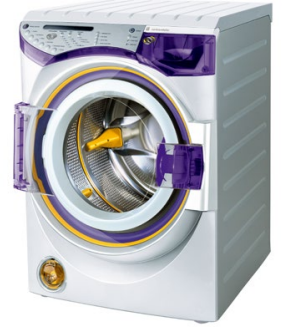

(a)

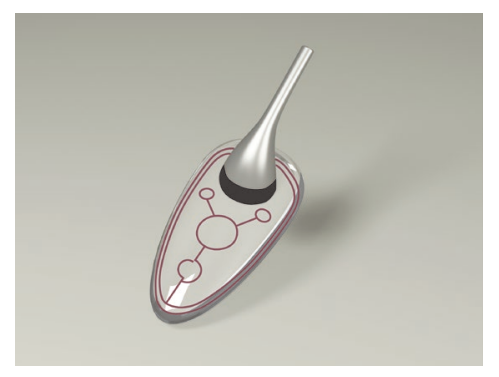

(b)

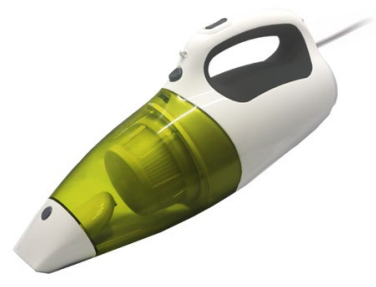

(c)

Figure 3. Product examples that fulfill the design intention 'improve product usability': (a) a washing machine, product example No. 18; (b) an iron, product example No. 5; (c) a vacuum cleaner, product example No. 11 .

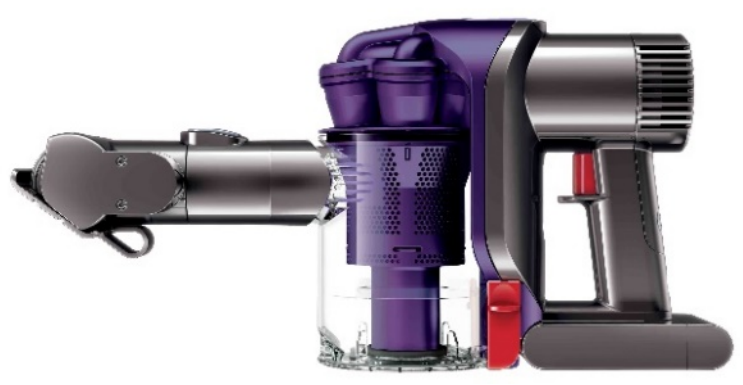

Figure 4. Product example that fulfils the design intention 'facilitate consumers' comprehension': a vacuum cleaner, product example No.12. 


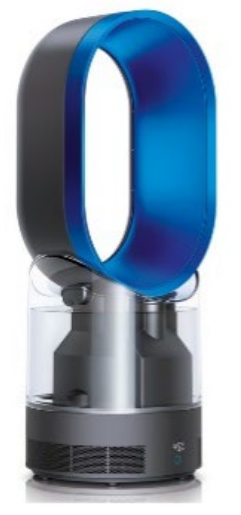

(a)

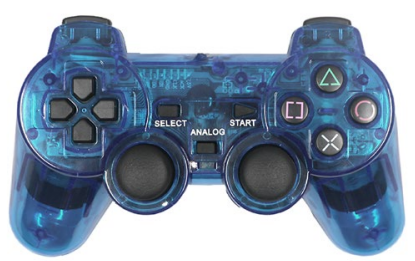

(b)

Figure 5. Product examples that fulfill the design intention 'demonstrate product functionality': (a) a humidifier, product example No. 14; (b) a game controller, product example No. 8.

70

60

50

40

30

20

10

0
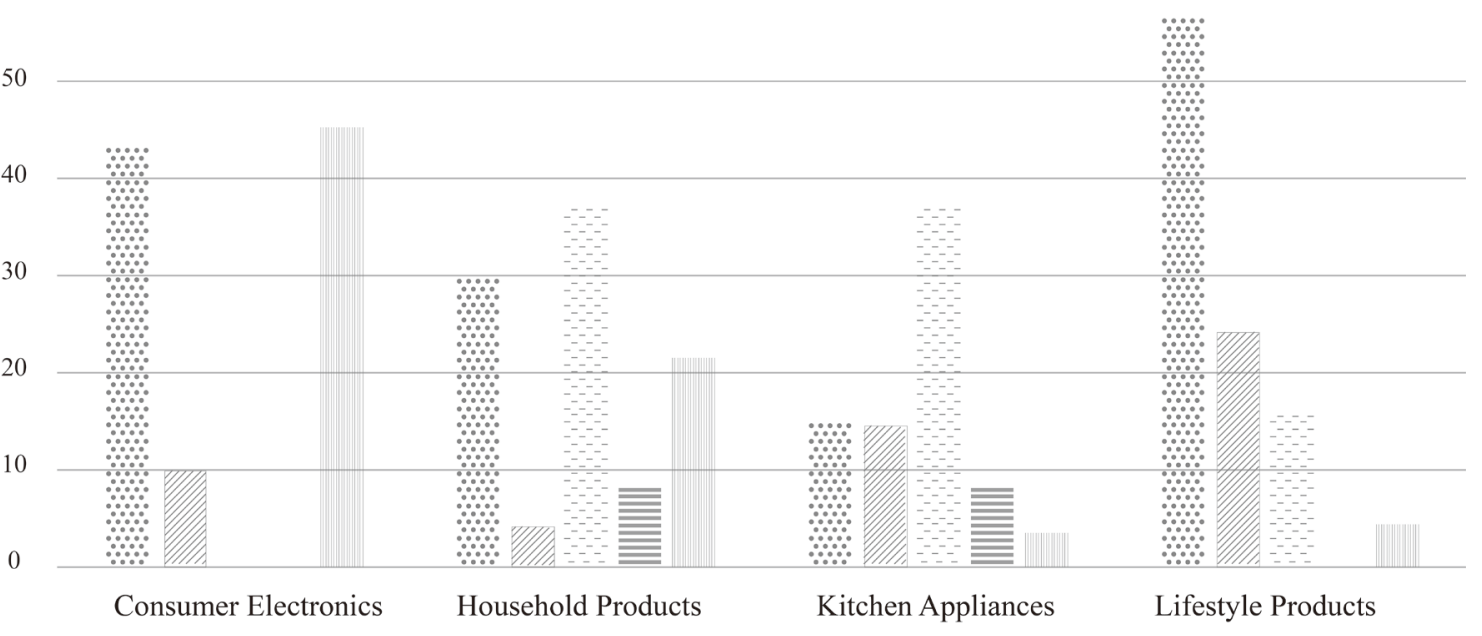

$\because \because \quad$ Enrich Visual Appeals Enrich Product Experience

Improve Product Usability 无 Facilitate Consumers' Comprehension

Demonstrate Product Functionality

Figure 6. Percentage of each design intention mentioned by the participants among the total number of mentioned design intentions across different product categories. 


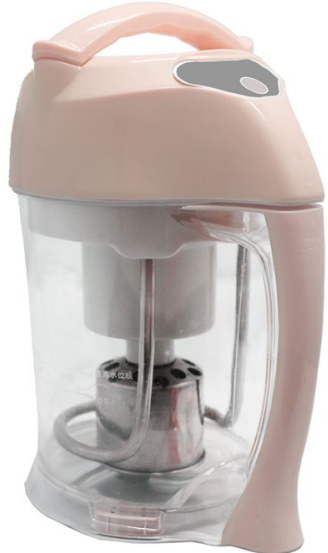

Figure 7. A soy milk maker, product example No. 6. 


\section{Figure Captions}

Figure 1. Product examples that fulfill the design intention 'enrich visual appeal': (a) a portable speaker, product example No. 9; (b) a hairdryer, product example No. 8; (c) an oil diffuser, product example No. 4; (d) a sound, product example No. 30.

Figure 2. Product examples that fulfill the design intention 'enrich product experience': (a) a coffee dripper, product example No. 25; (b) a stove, product example No. 20; (c) a radio, product example No. 27.

Figure 3. Product examples that fulfill the design intention 'improve product usability': (a) a washing machine, product example No. 18; (b) an iron, product example No. 5; (c) a vacuum cleaner, product example No. 11 .

Figure 4. Product example that fulfils the design intention 'facilitate consumers' comprehension': a vacuum cleaner, product example No.12.

Figure 5. Product examples that fulfill the design intention 'demonstrate product functionality': (a) a humidifier, product example No. 14; (b) a game controller, product example No. 8.

Figure 6. Percentage of each design intention mentioned by the participants among the total number of mentioned design intentions across different product categories.

Figure 7. A soy milk maker, product example No. 6. 